\title{
NOTES
}

\section{Thermal Properties of Monomeric, Dimeric, Trimeric, and Tetrameric Model Compounds for Biodegradable Poly(decamethylene sebacate)}

\author{
Yoshihiro OGawa, ${ }^{\dagger}$ Miki OKeda, and Naohide Matsumoto \\ Department of Chemistry, Faculty of Science, Kumamoto University, \\ Kurokami 2-39-1, Kumamoto 860-8555, Japan
}

(Received June 7, 2005; Accepted August 22, 2005; Published January 15, 2006)

\author{
KEY WORDS Aliphatic Polyesters / Model Compounds / Biodegradable / Thermal Properties / \\ Oligomers / \\ [DOI 10.1295/polymj.38.85]
}

In recent years, biodegradable aliphatic polyesters consisting of alkanediol and dicarboxylic acid have received considerable attention because the preparation of their polymers is relatively simple and they are much cheaper than other biodegradable polymers. ${ }^{1} \mathrm{Bi}$ odegradability is the most important property for this type of polyester, and so far, most studies have focused on the relation between structural elements and their biodegradability. ${ }^{2}$ The thermal properties of aliphatic polyesters have also been studied; however, the values obtained are uncertain. For example, poly (decamethylene sebacate) consisting of 1,10-decanediol and sebacic acid has been shown to have different melting points and heats of fusion by different investigators. ${ }^{3,4}$

Generally, polymers are polydisperse materials. This is due to the fact that polymer formation follows a random process. Therefore, it is difficult to obtain the equilibrium heat and entropy of fusion from polymer data. Normal alkanes are pure, and therefore, have been extensively studied as model compounds of polyethylene; the equilibrium heat and entropy of fusion were obtained from alkanes data. ${ }^{5}$ In addition, Garner showed that the heat and entropy of fusion of alkanes increase linearly with the number of methylene units, and he obtained the equilibrium temperature $\left(135^{\circ} \mathrm{C}\right)$ of polyethylene. ${ }^{6}$ Our research focused on aliphatic polyesters models with a high number of methylene units. Kink conformations can be observed in polymers with a low number of methylene groups; ${ }^{7}$ however an extended conformation was postulated for polyesters with long polymethylene sequences. ${ }^{8} \mathrm{~A}$ unit cell of polyester synthesized from sebacic acid and alkanediol ( $n=6$ or 12) contains two chain segments with an all trans conformation and a chain setting angle similar to that reported for polyethylene., ${ }^{9,10}$ The composition of such polyester polymers is char- acterized by an alternation of segments of methylene units and ester bonds. No reports on model compounds of aliphatic polyesters are available.

In this paper, polyester oligomers comprising repeating units of $-\mathrm{CO}\left(\mathrm{CH}_{2}\right)_{8} \mathrm{COO}\left(\mathrm{CH}_{2}\right)_{10} \mathrm{O}$ - and two terminal alkyl groups, as shown below, were synthesized, separated, and studied as model compounds of poly(decamethylene sebacate). The thermal properties of aliphatic polyester oligomers were systematically investigated as functions of the degree of polymerization, and the equilibrium melting temperature was calculated from the data on enthalpies and entropies of fusion.

$$
\begin{aligned}
& \mathrm{C}_{9} \mathrm{H}_{19} \mathrm{COO}\left(\mathrm{CH}_{2}\right)_{10} \mathrm{O}- \\
& {\left[\mathrm{CO}\left(\mathrm{CH}_{2}\right)_{8} \mathrm{COO}\left(\mathrm{CH}_{2}\right)_{10} \mathrm{O}\right]_{n-1} \mathrm{COC}_{9} \mathrm{H}_{19}} \\
& \quad \mathrm{C} 10-n(n=1,2,3,4)
\end{aligned}
$$

\section{EXPERIMENTAL}

\section{Materials}

Sebacic acid, 1,10-decanediol, and decanoic acid were purchased from Tokyo Kasei and were used without further purification. Other reagents and solvents were commercially available and were also used as received. Sebacic acid, 1,10-decanediol, and decanoic acid in a molar ratio of 2:3:2 together with a small amount of $p$-toluenesulfonic acid in toluene were heated to boiling in a flask for $24 \mathrm{~h}$. The flask was attached to a water separator equipped with a reflux condenser. A C10- $n$ series mixture was obtained. This mixture was separated and purified at room temperature by using a silica gel column. Toluene was used as an eluent. The results of mass spectra and elemental analysis were in good agreement with the

${ }^{\dagger}$ To whom correspondence should be addressed (Tel: +81-96-342-3392, FAX: +81-96-342-2751, E-mail: ogawa@ aster.sci.kumamoto-u.ac.jp). 
calculated values.

C10-1 Anal. Calcd for $\mathrm{C}_{30} \mathrm{H}_{58} \mathrm{O}_{4}: \mathrm{C}, 74.64 ; \mathrm{H}, 12.11$. Found: $\mathrm{C}, 74.57 ; \mathrm{H}, 12.55$. EIMS $m / 2$ (\%) 482 $\left(\mathrm{M}^{+}, 13\right), 370$ (31), 329 (22), 256 (37), 173 (40), 155 (42), 138 (95), 81 (61), 69 (100).

C10-2 Anal. Calcd for $\mathrm{C}_{50} \mathrm{H}_{94} \mathrm{O}_{8}: \mathrm{C}, 72.94 ; \mathrm{H}, 11.51$. Found: C, 73.12; H, 12.01. EIMS $m / 2$ (\%) 823 $\left(\mathrm{M}^{+}, 7\right), 650$ (22), 513 (20), 453 (33), 341 (100), 323 (23), 185 (22), 155 (48).

C10-3 Anal. Calcd for $\mathrm{C}_{70} \mathrm{H}_{130} \mathrm{O}_{12}$ : C, 72.24; $\mathrm{H}, 11.26$. Found: C, 71.91; H, 11.71. HRMS $m / z=1163.76$ $\left(\mathrm{M}^{+}\right.$, Calcd for $\left.\mathrm{C}_{70} \mathrm{H}_{130} \mathrm{O}_{12}: 1163.77\right)$.

C10-4 Anal. Calcd for $\mathrm{C}_{90} \mathrm{H}_{166} \mathrm{O}_{16}$ : C, 74.64; $\mathrm{H}, 12.11$. Found: C, 74.57; H, 12.55. HRMS $m / z=1503.97$ $\left(\mathrm{M}^{+}\right.$, Calcd for $\left.\mathrm{C}_{90} \mathrm{H}_{166} \mathrm{O}_{16}: 1504.27\right)$.

\section{Measurement}

The melting points and thermodynamic properties of C10- $n$ were measured on a Seiko DSC SSC560 differential scanning calorimeter at a heating rate of 5 and $0.5 \mathrm{~K} \mathrm{~min}^{-1}$. The heat quantity was computed from the DSC peak area using indium as the standard. The accuracy of the value was within $3 \%$.

\section{RESULTS AND DISCUSSION}

Figure 1 shows the DSC heating curves of C10- $n$. The monomer, dimer, trimer, and tetramer are perfectly separated and the sharpness of the peaks indicates the high purity of each C10- $n$. The heating curves

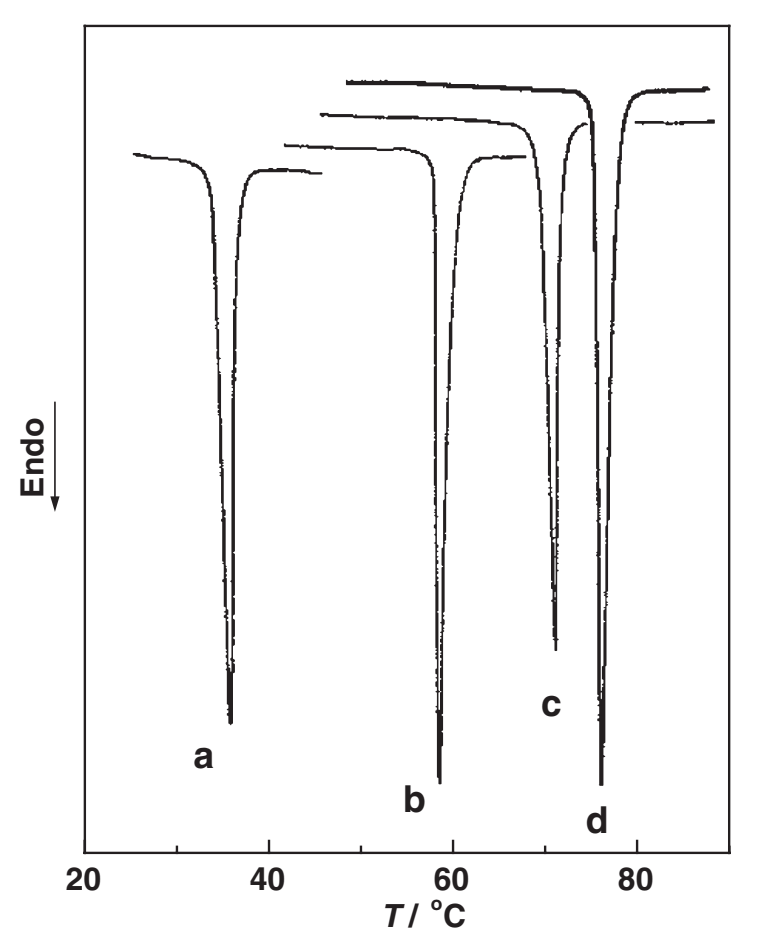

Figure 1. DSC heating curves of $\mathrm{C} 10$ series monomer, dimer, trimer, and tetramer.
Table I. Thermodynamic properties of $\mathrm{C} 10$ series monomer, dimer, trimer, and tetramer

\begin{tabular}{cccc}
\hline$n$ mer & $T_{\mathrm{m}} /{ }^{\circ} \mathrm{C}$ & $\Delta H / \mathrm{kJ} \mathrm{mol}^{-1}$ & $\Delta S / \mathrm{JK}^{-1} \mathrm{~mol}^{-1}$ \\
\hline 1 & 38.0 & 87.0 & 279 \\
2 & 59.2 & 162 & 487 \\
3 & 69.4 & 227 & 664 \\
4 & 75.3 & 288 & 827 \\
\hline
\end{tabular}

exhibit a single peak, which implies that no solidsolid transitions occur during heating. The melting temperatures of $\mathrm{C} 10-1, \mathrm{C} 10-2, \mathrm{C} 10-3$, and C10-4 were 38.0, 59.2, 69.4, and $75.3^{\circ} \mathrm{C}$, respectively, which were about $30^{\circ} \mathrm{C}$ lower than those of corresponding alkanes with the same carbon number. Both $\mathrm{C} 10-n$ series polyester oligomers showed a convergence of melting temperatures with increasing $n$.

Table I displays the thermal data obtained by DSC measurement. For the thermodynamic investigation of polymers, it is important to determine the enthalpy of fusion $\Delta h$ or entropy of fusion $\Delta s$ for every repeating unit. However, an accurate determination of $\Delta h$ or $\Delta s$ is usually difficult in the case of polymers because they lack perfect crystallinity. For example, according to different investigators, poly(decamethylene sebacate) has different melting temperatures $\left(73-80^{\circ} \mathrm{C}\right)$ and heats of fusion for each repeating unit (50.2$56.5 \mathrm{~kJ} / \mathrm{mol}){ }^{3}{ }^{3}$ This disagreement may be attributable to a difference in the polymerization degree and its distribution. In comparison, the model compound exhibits perfect crystallinity and a constant molecular weight, thus permitting an accurate determination of its $\Delta h$ or $\Delta s$, provided the effect of the end group is evaluated correctly. An approach has been proposed for the evaluation of a quantity per repeating unit of model compounds. C10- $n$ was defined as $\mathrm{T}-\mathrm{M}_{n}-\mathrm{T}$, where $\mathrm{M}$ and $\mathrm{T}$ represent the repeating unit and the terminal group, respectively, as shown below. ${ }^{11}$

$$
\begin{array}{ll}
-\left[\left(\mathrm{CH}_{2}\right)_{4} \mathrm{COO}\left(\mathrm{CH}_{2}\right)_{10} \mathrm{OCO}\left(\mathrm{CH}_{2}\right)_{4}\right]- & \mathrm{M} \\
\mathrm{CH}_{3}\left(\mathrm{CH}_{2}\right)_{4}- & \mathrm{T}
\end{array}
$$

Therefore, C10-1, C10-2, C10-3, and C10-4 may be represented as T-M-T, T-M-M-T, T-M-M-M-T, and T-M-M-M-M-T, respectively. The enthalpies of fusion for C10- $n$ were plotted as a function of $n$, as shown in Figure 2. The obtained linear function is expressed as

$$
\Delta H=66.8 n+24.0(\mathrm{~kJ} / \mathrm{mol})
$$

for the $\mathrm{C} 10$ series. This equation demonstrates the additivity of the contributions of the monomer units (M) and terminal groups (T). Therefore, eq 1 can be rewritten as $\Delta H=n \Delta h+\Delta h_{\mathrm{t}}$, where $\Delta h$ is the enthalpy change of fusion per repeating unit, and $\Delta h_{\mathrm{t}}$ is the sum of the enthalpy change of fusion for two terminal groups. The value of $\Delta h 66.8 \mathrm{~kJ} / \mathrm{mol}$ is approxi- 


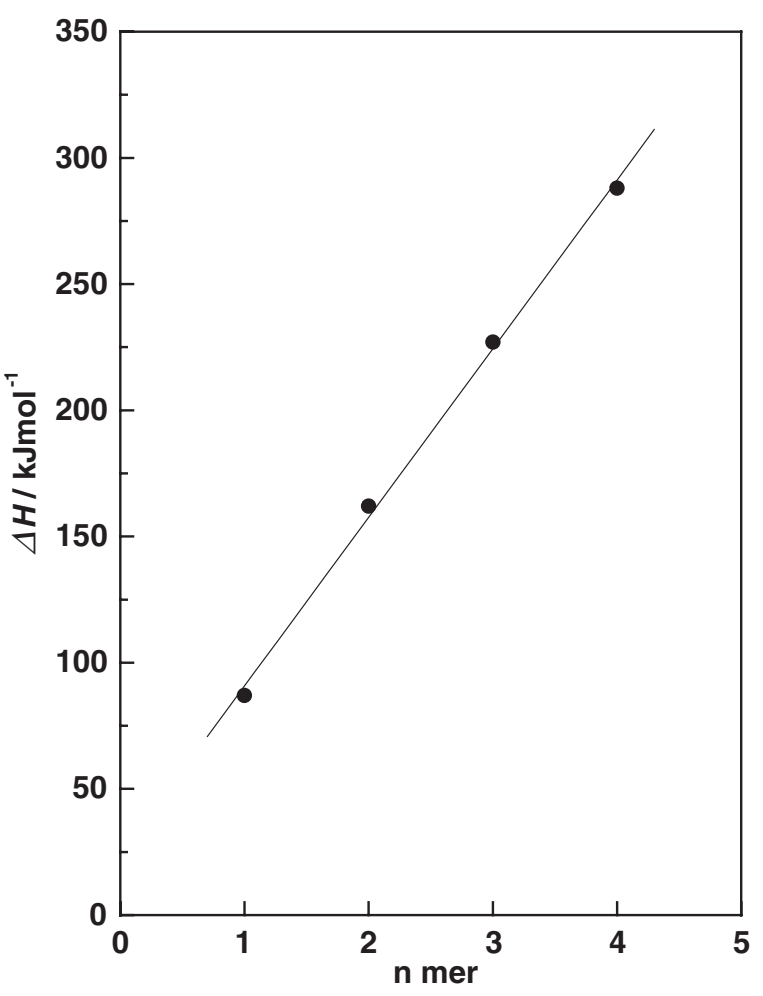

Figure 2. Dependence of heat of fusion of C10 series monomer, dimer, trimer, and tetramer on $n$.

mately 20-30\% greater than those of poly(decamethylene sebacate), which are $50.2,56.5$, and $51.5 \mathrm{~kJ} / \mathrm{mol}$.

Figure 3 shows the dependence of entropies of fusion on $n$ for the C10 series. The obtained linear function is expressed as

$$
\Delta S=182 n+109(\mathrm{~J} / \mathrm{K} \mathrm{mol})
$$

for C10- $n$. This equation also demonstrates the additivity of the contributions of the monomer units and terminal groups.

The melting points of polyesters are much lower than those of alkanes. For example, the melting point of $\mathrm{C} 10$ polyester was $73-80{ }^{\circ} \mathrm{C}^{3}$ and that of polyethylene was $120-140{ }^{\circ} \mathrm{C} .{ }^{5}$ This difference can be understood by comparing the thermal data on polyester oligomers and $n$-alkanes. The melting enthalpy and entropy of C10 tetramer are 288 and $827 \mathrm{~J} / \mathrm{K} \mathrm{mol}$ and those of $n$-alkanes that have the same carbon number are 222 and $578 \mathrm{~J} / \mathrm{Kmol}$ respectively. The melting temperature equation is represented by the expression $T_{\mathrm{m}}=\Delta H / \Delta S$. The melting point of the $\mathrm{C} 10$ tetramer is lower than that of the alkane because the melting entropy of the former is much greater than that of the latter.

The equilibrium melting point of an infinitely perfect crystal of linear polyethylene is an important feature in polymer crystallization theory; its value is a cause for significant disagreement. An equation for alkanes based on the linearity of $\Delta H$ and $\Delta S$ was giv-

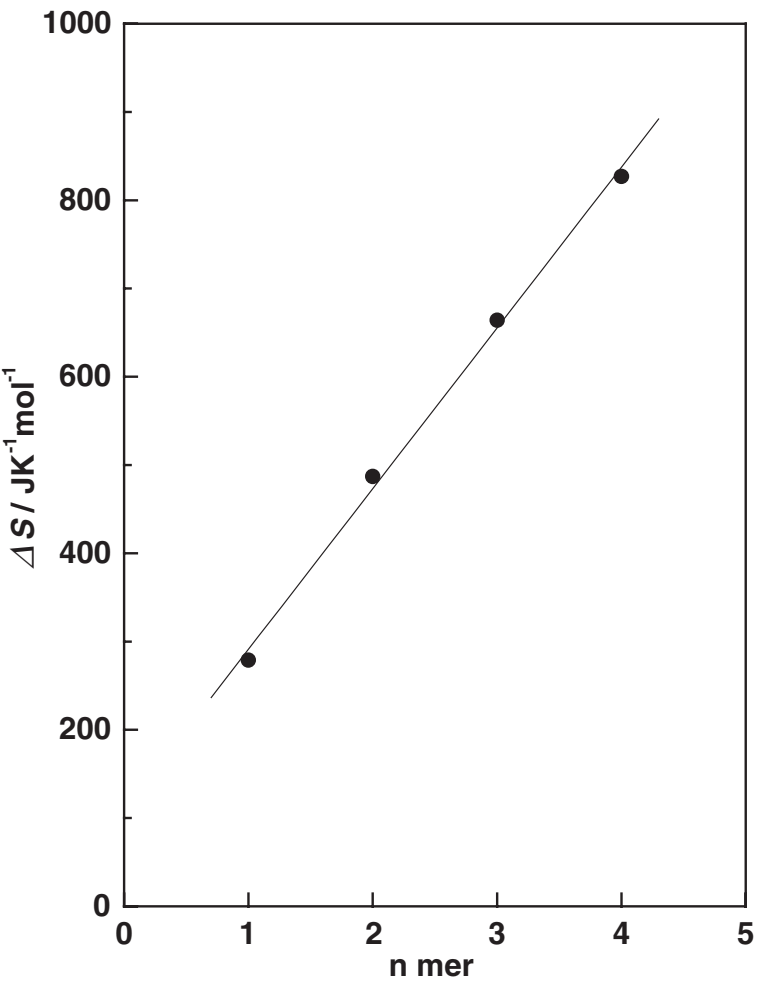

Figure 3. Dependence of entropy of fusion of $\mathrm{C} 10$ series monomer, dimer, trimer, and tetramer on $n$.

en by Broadhurst as $T_{\mathrm{m}}=414.3(n-1.5) /(n+5.0)$ and the equilibrium temperature was $414.3 \mathrm{~K} .{ }^{12}$ From eqs 1 and 2, the melting temperature equation for $\mathrm{C} 10$ is $T_{\mathrm{m}}=367(n+0.359) /(n+0.599)$. From this general equation, the equilibrium melting temperature, $T_{\infty}$, of poly(decamethylene sebacate) was obtained as $94^{\circ} \mathrm{C}(367 \mathrm{~K})$.

\section{REFERENCES}

1. T. Fujimaki, Polym. Degrad. Stab., 30, 7403 (1997).

2. I. Cho and K. Lee, Macromol. Chem. Phys., 198, 861 (1997).

3. J. Brandrup and E. H. Immergut, "Polymer Handbook," 3rd ed. John Wiley \& Sons, New York, N.Y., 1989.

4. H. Uyama, K. Inada, and S. Kobayashi, Polym. J., 32, 440 (2000).

5. B. Wunderlich, "Macromolecular Physics," Academic Press, New York, 3, 26 (1980).

6. W. E. Garner, K. van Bibber, and A. M. King, J. Chem. Soc. London, 1533 (1931).

7. P. A. Aylwin and R. H. Boyd, Polymer, 25, 323 (1984).

8. T. Kanamoto and K. Tanaka, J. Polym. Sci., Part A-2, 9, 2043 (1971).

9. E. Amelin, M. T. Casas, and J. Puiggali, Polymer, 42, 5695 (2001).

10. E. Amelin, A. Almontassir, L. Franco, and J. Puiggali, Macromolecules, 35, 3630 (2002).

11. Y. Ogawa, Polym. J., 28, 289 (1996).

12. M. G. Broadhurst, J. Res. Natl. Bur. Stand., 66A, 241 (1962). 